Rhode Island College

Digital Commons @ RIC

$1-1-2014$

\title{
Exploring Nurses' Knowledge about Heart Failure before and after the Implementation of a Heart Failure Education Program
}

Suzanne H. Richmond

Rhode Island College

Follow this and additional works at: https://digitalcommons.ric.edu/etd

Part of the Other Education Commons, and the Other Nursing Commons

\section{Recommended Citation}

Richmond, Suzanne H., "Exploring Nurses' Knowledge about Heart Failure before and after the Implementation of a Heart Failure Education Program" (2014). Master's Theses, Dissertations, Graduate Research and Major Papers Overview. 245.

https://digitalcommons.ric.edu/etd/245

This Major Paper is brought to you for free and open access by the Master's Theses, Dissertations, Graduate Research and Major Papers at Digital Commons @ RIC. It has been accepted for inclusion in Master's Theses, Dissertations, Graduate Research and Major Papers Overview by an authorized administrator of Digital Commons @ RIC. For more information, please contact digitalcommons@ric.edu. 
EXPLORING NURSES' KNOWLEDGE ABOUT HEART FAILURE BEFORE AND AFTER THE IMPLEMENTATION OF A HEART FAILURE EDUCATION PROGRAM

by

\author{
Suzanne Richmond \\ A Major Paper submitted in Partial Fulfillment of the \\ Requirements for the Degree of \\ Master of Science in Nursing \\ in \\ The School of Nursing \\ Rhode Island College \\ 2014
}




\section{Table of Contents}

Background and Significance of the Problem 1

Overview and Critique of the Literature 4

Theoretical Framework 12

$\begin{array}{ll}\text { Method } & 15\end{array}$

$\begin{array}{ll}\text { Results } & 20\end{array}$

$\begin{array}{lr}\text { Summary and Conclusions } & 24\end{array}$

Implications for Advanced Nursing Practice 28

$\begin{array}{ll}\text { References } & 30\end{array}$

$\begin{array}{ll}\text { Appendices } & 34\end{array}$

A. Informational Letter 34

B. Care Manager's Characteristics Survey 36

C. Nurse's Knowledge of Heart Failure Principles 37

D. Texas University Heart Failure Post Test 39

E. Consent Form 41 


\section{Acknowledgements}

This major project has taken a considerable amount of time, research, and perseverance to develop and complete. This project was made possible with the assistance, guidance, and support of a few key individuals. I am appreciative of those individuals who supported me throughout this project. I would like to thank all of my professors for their guidance, but especially Dr. Jeanne Schwager, for her patience and encouragement. Her attention to detail has been a valuable resource in the development and presentation of this project.

I would also like to thank my daughters, Kandace and Holly for their support and their computer expertise, making the technical aspect of this project manageable. Most of all I would like to thank my husband John, for his commitment to my pursuit of higher education, and his encouragement and understanding during the last few years. Without his help, this would not have been possible. 


\begin{abstract}
Heart failure (HF) has become a national epidemic, with 5.7 million Americans currently living with HF. Although HF is incurable, it is manageable if health care professionals apply current practice guidelines to patient teaching. Nurses are charged with providing comprehensive education about HF self-management and it is imperative they stay abreast of evidence-based guidelines. The purpose of this project was to explore the current HF knowledge of Home Based Primary Care (HBPC) registered nurse Care Managers employed at the Providence Veterans Administration Medical Center (PVAMC). The logic model and Knowles andragogy theory assisted this researcher in the creation of a clear, organized and systematic approach to assessing Care Managers' knowledge and in planning a HF education program that was sensitive to the needs of adult learners. Nine Care Managers participated in two HF educational meetings and completed the Texas Tech University HF on-line module. The Nurses Knowledge of Heart Failure Principles (NKHFP) questionnaire was administered to the Care Managers as pre and post-tests to identify gaps in knowledge prior to and following this $\mathrm{HF}$ education program. The Care Managers incorrectly answered pivotal questions related to HF, indicating they may not have the most current knowledge of HF principles. Although the study was limited by a small sample size, it confirmed similar results found in the literature from studies that included larger numbers of participants. These findings suggest the need for continuing education programs that develop nursing competencies in patient teaching of high risk populations, such as HF patients, to enhance disease self-management.
\end{abstract}


Exploring Nurses' Knowledge About Heart Failure Before and After the Implementation of a Heart Failure Education Program

\section{Background and Significance of the Problem}

Cardiovascular diseases (CVD) include all problems affecting the heart or blood vessels, such as myocardial infarction, cerebral vascular accident, hypertention, coronary heart disease, aortic aneurism, and heart failure (Tomaselli, Harty, Horton, \& Schoeberl, 2011). These diseases are a major threat to public health and are the leading cause of death worldwide. According to the World Health Organization, approximately 17.3 million deaths in 2008 were attributable to CVD. In the United States, CVD are the primary cause of death for over 2150 Americans each day, representing approximately one death every 40 seconds (Go, et al., 2012). The incidence of CVD globally is increasing at an alarming rate and is expected to remain the number one cause of death. Epidemiologists project that $40.5 \%$ of the U.S. population may be affected by CVD by the year 2030 (Heidenreich, et al., 2011).

In addition to the high incidence and prevalence of the diseases, CVD are the cause of premature mortality, as reflected in the fact that 150,000 individuals under the age of sixty-five died from CVD in 2009 (Go, et al., 2013). Heart failure (HF) provides an example of this premature mortality. Currently in this country there are approximately 5.7 million Americans living with HF, and once diagnosed, the average life expectancy of individuals over sixty-five years of age is 1.7 years for males and 3.2 years for females (Moser \& Mann, 2002). Heart failure (HF) is a chronic condition in which the heart is unable to effectively pump blood to accommodate the body's demands. The probability of heart failure increases with age and 
individuals over the age of sixty-five are at a greater risk for the disease. The risk increases dramatically for those over eighty years of age, and since this segment of the population is one of the fastest growing; the prevalence of heart failure is projected to increase exponentially (Heidenreich, et al., 2011). Indeed, a national epidemic of heart failure is anticipated as a high percentage of the population ages (Schocken, et al., 2008).

Health care service utilization is high for those diagnosed with HF, and since the disease is difficult to manage, HF patients have a thirty to forty percent hospital readmission rate within six months of hospitalization. The total direct and indirect costs of heart failure include frequent hospitalizations, surgical procedures, medical appointments, medications, and loss of income; all of which contribute to the 20.9 billion dollar cost of HF in the U.S. in 2012 (Heidenreich, et al., 2013). To reduce the costs of this disease, the American Heart Association, the American College of Cardiology and other professional societies have developed treatment guidelines for professionals to utilize when caring for HF patients (Heidenreich, et al., 2013). If these standards of care are used consistently by health professionals, the incidence of heart failure can be dramatically reduced and the outcomes of care improved (Heidenreich, et al., 2013).

Heart failure is incurable, but its effects can be mitigated if health care professionals partner with affected persons in an evidence-based approach to disease management. Nurses are a critical part of the health care team and must know the most current HF practice guidelines. Applying this knowledge, nurses can provide patients with comprehensive education about HF disease self-management, helping to reduce morbidity and mortality and 
improve quality of life. Given the important role of nurses in teaching HF patients, the purpose of this project is to explore the knowledge of heart failure management among HBPC registered nurse Care Managers employed at the PVAMC. 


\section{Overview and Critique of Literature}

A literature search was conducted using the following databases: Cumulative Index to Nursing and Allied Health Literature (CINAHL), ProQuest, Pub Med and Medline from the years 2002-2013. The key words entered into the databases included: HF in adults, HF care guidelines, HF education programs, HF self-management, and HF teaching tools. Additionally, the key words: nurse education and adult learning theories were searched to guide this researcher in the development of a HF teaching program for nurses. Nursing journal articles with information related to current HF practice guidelines and nursing education programs were reviewed and evaluated for their content and usefulness for this project.

\section{Heart Failure}

Heart failure, as defined by the American Heart Association (AHA), is a chronic and progressive condition in which the weakened heart muscle is unable to keep up with the body's need for blood and oxygen. The heart will attempt to compensate for its declining functioning by initially enlarging and stretching to improve contractility and efficiency. The heart increases it's size and rate which allows it to temporarily pump larger volumes of blood and oxygen to meet the body's demands. These compensatory mechanisms are initially able to mask symptoms of heart failure until the heart is no longer able to offset it's deteriorating ability to function. The more common symptoms of heart failure include fatigue, shortness of breath, cough, swelling of the abdomen, swelling of the lower extremities, and weight gain (DeBakey \& Gotto Jr., 2012). 
There are two types of HF; left-sided and right-sided heart failure, and both conditions affect the heart's ability to perform normally. Left-sided heart failure occurs when the left ventricle loses it's ability to relax or to contract causing insufficient blood and oxygen to be pumped out into circulation. Right-sided failure is caused when the left ventricle's inefficiency causes an increase in fluid pressure that prohibits the right side from functioning and results in the slowing of blood returning to the heart. Right-sided heart failure symptoms include vein swelling and congestion, most notable in the lower extremities (DeBakey \& Gotto Jr., 2012).

\section{Heart Failure Classifications}

Patients diagnosed with HF are categorized by the severity of their symptoms and their physical limitations during exertion. A system was developed by the New York Heart Association (1994) that includes two classifications; functional capacity and objective assessment. The functional classification system consists of four classes. Class 1 patients are asymptomatic and have no physical limitations related to cardiac function. In Class 2, patients experience some physical limitations during exertion such as shortness of breath, but their symptoms resolve with rest. Class 3 patients have significant impairment of physical activity due to HF symptoms and may or may not have symptoms at rest. Class 4 patients are unable to perform any physical activity without significant symptoms or discomfort that may also be present at rest.

The objective assessment classifies patients into four groups, $A$ through $D$, with the class being determined by the extent of the heart disease and associated physical activity limitation. 
Class A HF patients are asymptomatic and have no evidence of heart disease. Class B patients have mild observable heart disease and mild heart failure symptoms that resolve with rest. Class $\mathrm{C}$ denotes moderate to severe heart disease and limitations of physical activities and comfort only at rest. Class D patients have severe heart disease with equally severe physical limitations and experience their symptoms even at rest (Association, 1994).

The functional classification and objective assessment scores define the patient's severity of their HF, and as heart function declines, there may also be a decline in the patient's ability to participate in the self-management of their HF symptoms. The HF education provided by the nurse, therefore, should be tailored to the functional classification and objective assessment of the patient.

\section{Heart Failure Management}

The Centers for Medicare and Medicaid Services (CMS), the largest health care insurers in the country, have recently changed their policies for reimbursement with the establishment of the CMS Innovation Center and the Hospital Readmissions Reduction Program. The Innovation Center was established by section 1115A of the Social Security Act (as added by section 3021 of the Affordable Care Act). Congress created the Innovation Center for the purpose of testing "innovative payment and service delivery models to reduce program expenditures ... while preserving or enhancing the quality of care" for those individuals who receive Medicare, Medicaid, or Children's Health Insurance Program (CHIP) benefits. 
The Center solicited stakeholders; clinicians, health systems, community leaders, and other innovators throughout the country to develop new models intended to reduce costs and improve patient outcomes. Each model must either reduce spending without reducing the quality of care, or improve the quality of care without increasing spending, and must not deny or limit the coverage or provision of any benefits (About the cms innovation center, 2012). The development of new and innovative service delivery models encourages health professionals to strive to achieve better patient outcomes, rewarding them financially for their successes.

Another important change in the reimbursement system was due to the Hospital Readmission Reduction Program. Under this program, targeted at discharges beginning on or after October 1, 2012, an adjustment is made to the base operating Diagnosis Related Group payment to account for excess readmissions. A hospital's excess readmission ratio is a measure of its readmission performance compared to the national average for its set of patients for each of the following three conditions: acute myocardial infarction, heart failure and pneumonia. A readmission generally refers to an admission to an acute care hospital paid under the IPPS (Inpatient Prospective Payment System) within 30 days of a discharge from the same or another acute care hospital (Acute Care Hospital Inpatient Prospective Payment System, 2013). Hospitals are challenged to improve care processes beyond the inpatient setting for patients to reduce the incidence of readmissions. Physicians and other health care providers, particularly nurses, are being held accountable for the prevention of exacerbations of chronic diseases such as HF that contribute to poor patient outcomes. 


\section{Heart Failure Guidelines}

To address the HF epidemic, the AHA and the American College of Cardiology (ACC) began the Get With the Guidelines Heart Failure program in 2008. The guidelines direct hospitals in implementing the latest scientific guidelines for the care and education of hospitalized HF patients to reduce hospital readmissions and improve outcomes. The Get With the Guidelines program provides professionals with educational resources, a clinical toolkit, and patient educational materials and resources to improve heart failure management (American Heart Association, 2014). The AHA guidelines include nine domains to be included in heart failure teaching programs; including symptom recognition, exercise recommendations, medication use, indications and adherence, daily weights, information regarding modifiable risks, dietary restrictions, follow up appointments, discharge instructions and, when appropriate, end-of-life options (Get with the guidelines heart failure patient education prior to hospital discharge, 2011).

The effects of the AHA guidelines on HF patient outcomes have been evaluated by federal agencies. According to the data collected by CMS from the Hospital Compare website, data released in August of 2011 found only small changes to the hospital readmissions rates, when comparing the data for the years 2007 through 2010 against data for the years between 2006 and 2009. For patients discharged with a diagnosis of HF, the hospital readmission rate was $24.8 \%$ (2007-2010) as compared with $24.5 \%$ (2006-2009). Therefore, the readmission rates slightly increased for heart failure (TF: Target heart failure, 2011). There may be many causes 
for this slight increase in the HF readmission rate, such as the increase in life expectancy. The guidelines, however, have helped standardize HF management practices and should continue to be utilized and improved.

\section{Heart Failure Self-Management}

Heart failure symptom self-management is critical to a patient's quality of life and inadequate self-management of symptoms may lead to hospital re-admission or early mortality. Self-care is defined as a naturalistic decision-making process that patients use in the choice of behaviors that maintain physiological stability (symptom monitoring and treatment adherence) and the response to symptoms when they occur (Riegel et al., 2009). There are many causes of hospital readmissions for HF exacerbation, such as medication non-adherence and the inability to recognize and seek early medical interventions for HF symptoms.

Patient education reduces the probability of non-adherence and aids in early detection of changes in body weight and clinical status (Willette, Surrells, Davis, \& Bush, 2007). To provide effective patient education, nurses' must have current knowledge so that patients can be assured of basic information about HF self-management skills before they are discharged from the hospital (Albert et al., 2002).

HF symptom management is a collaborative undertaking and must include the patient and family, physician, nurse and other health care professionals to be successful. Nurses guide patients in the integration of symptom management into daily routines for early recognition of slight changes that may require self-initiated treatment strategies. Patients need education in 
disease self-management and behavior change to control symptoms and maintain function. Patients have primary responsibility for their disease management but may not have the information, motivation, or skills to implement the recommended lifestyle changes. Strategies such as daily weight monitoring, medication adherence and follow up medical appointments may help patients new to HF or those who would need a more structured approach.

Self-care is a decision-making process that uses the prefrontal cortex. Thus, it is not surprising that deficits in memory, attention and executive function may impair the perception and interpretation of, as well as reasoning about, early symptoms (Riegel et al., 2009). Patients with cognitive impairment may need the support and assistance of family members or caregivers to manage HF symptoms. Caregivers providing care for a patient at home often assume responsibility for medication administration, shopping, providing meals and personal care. It is, therefore, imperative that hospital nurses include caregivers in teaching regarding HF prior to the hospital discharge. Once home, the patient and caregiver may require further teaching by visiting nurses to assist them with HF symptom and disease management.

\section{Home Health Nurses}

One of the most common diagnoses of patients requiring home health care is $\mathrm{HF}$ and given the chronic nature of $\mathrm{HF}$, most self-management occurs in the home. Education and counseling are essential aspects that form the foundation upon which self-care and symptom management interventions are based. In a study by Albert et al., it was shown that comprehensive education of patient and family, including a review of medications, coupled with intensive follow-up, can decrease the readmission rate (Albert et al., 2002). In another 
study of home-based care after discharge, a nurse visited the patient after hospital discharge to teach about HF and medications. A reduction in HF events ( 38 vs $51 ; P=.04$ ) and unplanned readmissions (68 vs 118; $P=.03$ ) was seen in the patients receiving the follow up visit at home, as compared with the control group (Paul, 2008, p. 79). Further studies like this one are needed to strengthen the evidence for the value of home-based nursing education to reduce hospitalizations and to improve patient outcomes.

The nurse's role is to facilitate development of HF self-management skills through evidenced-based education of patients and caregivers. The ANA defines evidenced based nursing (EBN) as "an integration of the best evidence available, nursing expertise and the values and preferences of the individuals, families and communities served ("Evidence based nursing position statement," 2005, para. 4).

According to a study by Fowler, home care nurses themselves may require ongoing $\mathrm{HF}$ education to remain current with evidenced based practice guidelines. Study results demonstrated that home care and public health nurses had some knowledge of HF selfmanagement principles, but perhaps not to the level where they could provide high-quality care to patients with HF (Fowler, 2012). Still another study showed that nurses who teach patients should receive ongoing education to ensure that the information taught to patients is consistent in content, because patients who receive conflicting instructions may become confused (Paul, 2008). 


\section{Theoretical Framework}

\section{Logic Model}

The logic model served as a framework for the HF education program, which was developed by applying the principles of the W.K. Kellogg Foundations' model for program development (W.K. Kellogg Foundation, 2004). The logic model is used in many settings to graphically represent key parts of a program and their relationship to one another as they relate to a program development project. This model assists the program planner in first defining the interrelated components and then evaluating the causal impact each has on one another and to the program's success. This model assisted this researcher in the creation of a clear, organized, and systematic approach to planning a well-constructed HF education program.

The initial phase of the logic model is the description of the overall purpose, relevant participants and program goals. The second phase addresses inputs or resources that may already exist or be needed to achieve the programs goals. It is appropriate to utilize existing resources to save time and money. Resources that need to be obtained are the time needed to complete the activities, the space in which to hold or complete the activities, and finances for the production of written materials and guides. It is important to secure the necessary resources during the planning phase, prior to initiation of the program, as a loss of one of the necessary resources could prevent the realization of the project.

Next, the program implementation phase is developed and learning activities determined after examining the preferred learning styles of the participants. Data collection is 
planned prior to beginning the project, but the type of data to be collected should be predetermined and collected at regular intervals as appropriate. The time to complete the planned activities, presentations, tests or surveys should be determined prior to administration to allow adequate time for completion. It is often important to pilot the components of the learning activities with a small group of participants to make adjustments prior to recreating it for a large group.

The intended or desired initial, intermediate and ultimate outcomes are formulated during the program development process, but it is during the evaluation phase that the outcomes are analyzed. The model is used throughout the planning phase as a component of a formative evaluation and after completion of the program as part of the summative evaluation process. The final step in the logic model is the dissemination of the program, its outcomes, short comings and implications for further use.

\section{Andragogy Theory}

Knowles andragogy theory was applied to the development of the learning activities for the Care Managers' HF education program. Knowles' andragogy theory describes assumptions about adult learners based upon six principles: adults need to know the benefits and value of what is to be learned, adults want to be autonomous and self-directed, adults have a variety of life experiences that should not be ignored, adults learn better when they see an immediate need, adults are motivated to learn when the content relates to real-life situations and adults are highly motivated by internal pressures (Knowles, 1980). The HF program was designed with these six principles in mind to insure that Care Managers would be motivated to take part in 
the in-services and learning activities and therefore have a desire to complete each phase of the program.

The Nurses Knowledge of Heart Failure Principles questionnaire was administered to the Care Managers prompting them to draw on their past experiences with HF symptom management, thereby generating internal motivation for learning about current guidelines for HF symptom management. This researcher promoted self-direction among the Care Managers by involving them in the learning process and by cultivating their ability to determine individual learning objectives. Care Managers were also guided in the identification of gaps between their knowledge of HF and the current HF guidelines during all phases of the program. 


\section{Methods}

\section{Purpose}

The purpose of the project was to explore the knowledge base of HBPC registered nurse Care Managers regarding HF guidelines, evidence-based nursing interventions, and HF patient self-care principles prior to, and following participation in the HF education program. This researcher was interested in knowing if the HBPC Care Managers had current, evidence-based knowledge of HF principles and could, therefore, provide consistency in their education of HF patients.

Site

The HF education program was implemented at the HBPC Department of the PVAMC located in Rhode Island.

\section{Sample/participants}

The sample consisted of nine nurse Care Managers who worked in the HBPC program at the PVAMC. Participant ages ranged from 35 to 65 years. All of the Care Managers spoke English and had worked in the HBPC Department for at least two years. There was a $100 \%$ participation rate of HBPC Care Managers in the HF education program.

\section{Planning phase}

The researcher met with the HBPC Program Manager to discuss the need for an organized HF education program. The Program Manager was responsible for ensuring that Care Managers had educational opportunities and used evidence-based practices when caring for patients. After a review of nurse Care Manager in-service topics, it was noted that there had 
not been any education regarding HF for the past few years. The HBPC Program Manager approved the proposed HF program content and consented to the scheduling of learning activities. The researcher then scheduled the dates and times of educational meetings, which were integrated into the HBPC annual education calendar.

\section{Procedures}

The project was conducted between January and March of 2014 , following approval by the Institutional Review Boards of the PVAMC and Rhode Island College. An informational letter (Appendix A) was sent to the nine potential participants via email, explaining the purpose and content of the HF program. The letter also explained the procedure to be used to create a unique identifier for use with the pre- and post-test surveys, to insure the results would be anonymous and not linked to job performance.

Care Managers were asked to answer questions about their educational level, past cardiac patient experience, and level of confidence in their current knowledge of heart failure principles. Data collection included use of a multiple choice/Likert scale (Appendix B), the NKHFP survey (Appendix C) and the Texas University HF module post-test (Appendix D).

The Consent Document (Appendix E) was sent to the Care Managers with information regarding the procedures, risks, benefits, confidentiality and voluntary participation. If they were interested in participating, Care Managers were asked to complete the form and bring it with them to the first HF education meeting. The Care Managers were informed that there was no compensation for participation in the program, no identified risks, and that the anticipated 
benefits may be increased knowledge of evidence-based HF treatment guidelines and symptom management.

The first scheduled education meeting took place in February of 2014, in a large conference room at the PVAMC. Each Care Manager was given a folder which contained the agenda, information concerning the Texas University HF module, copies of the VAMC website HF resources, a HF Handbook developed by the Louis Stokes Cleveland VAMC, and the Nurses Knowledge of Heart Failure Education Principles survey.

Prior to the NKHFP survey, the Care Managers were asked to answer questions about their educational level, past cardiac patient experience, and level of confidence in their current knowledge of HF. Care Managers were then asked to sit at a distance from one another and to remain silent during administration of the NKHFP survey. Participants were coached in the creation of their unique survey identifier, consisting of three elements; the initial of their father's first name, the initial of their mother's first name, and the number of their older siblings. The researcher then directed them to complete the 20-question, true or false NKHFP survey.

After collecting this baseline data, the researcher informed the Care Managers about the HF resources located in the Talent Management System (TMS) and the need to complete the Texas Tech University online HF learning module and post-test. The TMS system is regularly accessed by all HBPC nurses for their mandatory and optional education programs, using either a PVAMC-issued laptop computer or a desk-top computer. For their convenience, participants were afforded the option to complete the TMS system HF module in their office or at home. 
A review and discussion of the HF Handbook followed, covering an overview of the heart, causes of HF, diagnostics, symptom management, medications, surgeries, and healthy life-style choices. Prior to adjourning, participants were reminded to complete the on-line HF module and post-test prior to the second education meeting.

At the beginning of the second education meeting, the researcher administered the NKHFP post-test survey and collected the on-line HF module post-tests from the Care Managers. These documents were then sealed in a manila envelope and placed in a locked drawer. A copy of the NKHFP article by Albert and colleagues was then distributed, along with the survey answer key for immediate review and discussion.

\section{Measurement}

Measurement of Care Manager's HF knowledge was achieved via administration of the Nurses Knowledge of Heart Failure Education Principles (NKHFP) questionnaire. The questionnaire was administered as a pre- or post-test at each of the two HF education meetings to assess participants' knowledge prior to and following HF program learning activities. Another measure of Care Managers' knowledge of HF was the post-test associated with the TMS system online HF learning module.

\section{Ethical considerations}

There were no ethical concerns or risks associated with this HF education program. The anonymity of the participating Care Managers' responses was assured and maintained by creating a unique survey identifier. The participants received an informational letter (Appendix A) explaining the program prior to its initiation and were informed that their participation was 
purely voluntary. The interested Care Managers then read and signed the consent form and returned it to the researcher at the first education meeting. The project was integrated into the Care Managers annual education calendar and was offered during their usual work hours.

\section{Data Analysis}

The pre- and post-test NKHFP scores and the HF module post-test scores were recorded, tabulated, and analyzed for improvement in Care Manager's HF knowledge. The Care Managers' characteristics were compared with their test scores to identify any patterns associated with education level, past experience, and level of confidence regarding current knowledge of HF principles. 


\section{Results}

Nine Care Managers participated in the HF education program and each completed the twenty questions NKHFP pre- and post-survey, as well as the HF online module post-test. Care Manager's previous employment setting, education level, care management experience, and confidence level regarding their knowledge of heart failure principles were summarized in Figures 1- 4.

\section{Employment Settings Prior to HBPC}

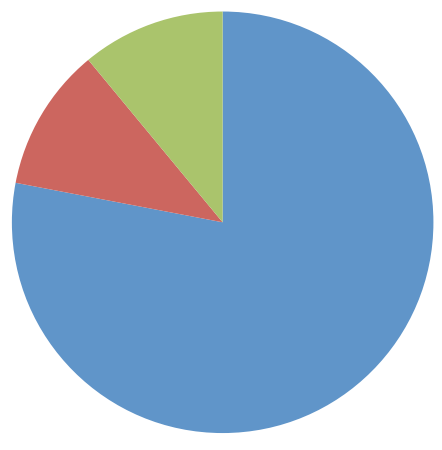

Home Care $78 \%$

Emergency Dept. 11\%

Cardiac unit/ICU 11\%

Figure 1. Care Manager's previous employment settings.

Highest Level of Nursing Education

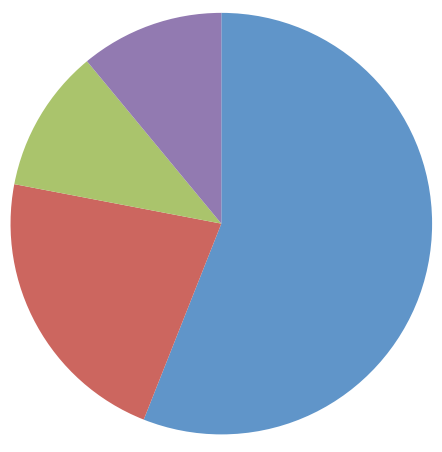

Bachelor's Degree 56\%

Associates Degree 22\%

Diploma $11 \%$

Master's Degree 11\%

Figure 2. Care Manager's highest level of nursing education. 
Total Years of Care Management Experience

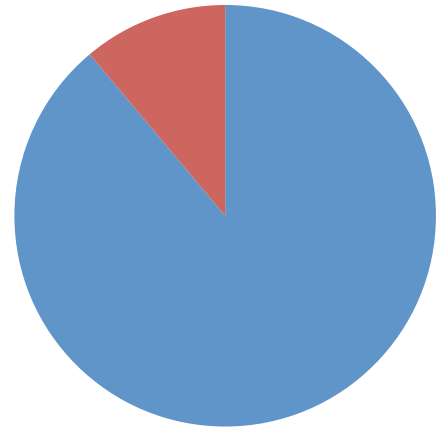

More than 6 years $88 \%$

$4-6$ years $11 \%$

less than 1 year $0 \%$

$1-3$ years $0 \%$

Figure 3. Total years of care management experience.

\section{Current Level of Confidence Regarding HF Education Principles}

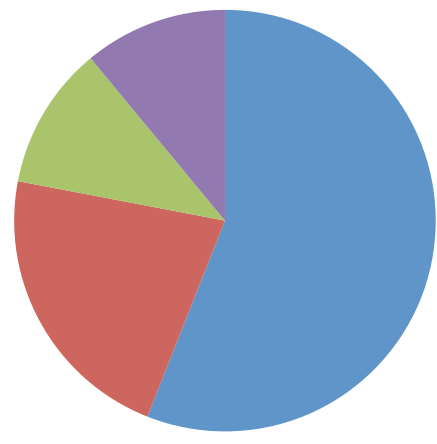

Somewhat Confident 56\%

Neutral 22\%

Very Confident $11 \%$

Not Very $11 \%$

Figure 4. Care Manager's current level of confidence regarding HF education principles.

The NKHFP pre-test survey scores ranged from 60 to 90 out of a possible 100 points,

with a mean score of 74.4. The post-test scores ranged from 65 to 95 out of a possible 100

points, with a mean score of 77.7. Three participant's post-test scores improved, four

participant's scores remained the same, while two of the participant's scores decreased. Table

1 illustrates each participants score on the pre- and post-test and the differences in the scores.

Table 1. Pre-test, post-test, and differences in participants scores on the NKHFP survey. 


\begin{tabular}{|llll|}
\hline Participant identifiers & Pre-test & Post-test & Difference in scores \\
\hline WD2 & 60 & 75 & 15 \\
\hline GM6 & 75 & 75 & 0 \\
\hline HJ3 & 75 & 70 & -5 \\
\hline EC1 & 75 & 75 & 0 \\
\hline EB2 & 70 & 90 & 20 \\
\hline FM4 & 80 & 80 & 0 \\
\hline LA0 & & \\
\hline GL3 & 75 & 75 & 0 \\
\hline JE1 & 90 & 95 & 5 \\
\hline
\end{tabular}

\begin{tabular}{llll}
\hline Mean scores & $74.4 \%$ & $77.7 \%$ & $3.33 \%$
\end{tabular}

The participants completed the Texas University HF online module, focusing on the pathophysiology, etiology, and treatment options for congestive HF. After completing the HF module, Care Managers submitted the module's post-test to the researcher for analysis.

The post-test scores ranged from 40 to100 out of a possible 100, and the mean score was 74.4\%. The results are shown in table 2. The participants' mean scores on the HF module posttest were the same as the mean scores on the NKHFP pre-test, $74.4 \%$. 
Table 2. Participants post-test scores for the Texas University HF online module.

\begin{tabular}{|l|l|}
\hline Identifier & 60 \\
\hline WD2 & 70 \\
\hline GM6 & 70 \\
\hline HJ3 & 60 \\
\hline EC1 & 90 \\
\hline EB2 & 90 \\
\hline FM4 & 100 \\
\hline LA0 & 90 \\
\hline GL3 & 40 \\
\hline JE1 & $74.4 \%$ \\
\hline Mean & \\
\hline
\end{tabular}

Summary and Conclusions 
The purpose of the project was to explore the knowledge base of HBPC registered nurse Care Managers regarding HF guidelines, evidence-based nursing interventions, and HF patient self-care principles prior to and following participation in a HF education program. This researcher was interested in knowing if the HBPC Care Managers had current, evidence-based knowledge of HF principles and could, therefore, provide consistency in their education of HF patients. The study had limitations due to the small sample size of nine Care Managers; nevertheless it confirmed results of previous studies with larger samples of participants; such as those conducted by Albert et. al., Willette et. al., and Mahramus et. al. In each of their studies, nurses incorrectly answered pivotal questions related to HF self-management, indicating that nurses may not have the most current knowledge in HF principles and are therefore unable to instruct patients in HF symptom management proficiently.

The educational level was not related to the Care Managers' performance on the NKHFP surveys. The mean score was $74 \%$ for the six Care Managers with a Bachelor's Degree and the one with a Master's Degree. The two Care Managers with an Associate's Degree and the one with a Diploma achieved a mean score of $75 \%$, outperforming the Care Managers with a higher degree by one percent.

Two of the Care Managers had experience in the Intensive Care Unit (ICU) and the Emergency Department (ED) and achieved a mean score of $65 \%$ on the pre-test. The other seven Care Managers who had home care experience achieved a mean score of $77 \%$, significantly outperforming the Care Managers with backgrounds in the ICU and ED. Based on this limited data, it seems that nurses who transfer from acute care settings to home care may 
need additional education in chronic disease self-management principles. The Care Managers collectively reported over six years of home care experience, with only one Care Manager reporting between 4-6 years of home care experience. The years of experience in home care, therefore, did not seem to determine the Care Managers performance on the pre-test questionnaire.

The Care Managers were asked to evaluate their confidence level in their knowledge of HF principles, and six of them identified themselves as very confident or somewhat confident. The remaining three Care Managers identified their confidence level as neutral or not very confident. The very confident and somewhat confident Care Managers attained a mean posttest score of $71 \%$ and the three neutral and not very confident Care Managers attained a mean score of $82 \%$. This demonstrated that the confidence levels of the Care Managers did not correlate with their level of knowledge, posing the potential problem that overconfidence may deter nurses from pursuing continuing education related to HF.

The Care Managers in this study answered questions fifteen, sixteen and eighteen incorrectly more than the other questions on the NKHFP survey, replicating the results of many of the other studies found in the literature. Question fifteen related to a patient's weight gain, and asked if the patient's weight today should be compared to yesterday's weight or the patient's dry weight. Most of the participants (67\%) answered this question incorrectly. The Care Managers later stated they had not heard of a dry weight being used in HF symptom management. Evidenced-based research recommends that a dry weight be determined for 
each patient by their physician and that this weight should be used to evaluate the patient's condition (Grady, Dracup, \& Kennedy, 2000).

Question sixteen asked if the physician should be notified when a patient's blood pressure is $80 / 50$ without any other HF symptoms. The Care Managers answered this question incorrectly $89 \%$ of the time and later stated that they felt this low blood pressure was a significant finding. The ACC/AHA reports that it is acceptable for a patient to present with a systolic blood pressure of 80 if otherwise asymptomatic (Grady, Dracup, \& Kennedy, 2000). The HF principles state that a physician does not need to be contacted in the absence of lightheadedness.

Question eighteen asked if the physician should be contacted when a patient described lightheadedness on arising that subsided within 10-15 minutes. The Care Managers answered this question incorrectly $56 \%$ of the time, apparently unaware that transient lightheadedness is often associated with medications used in HF (Willette, Surrells, Davis, \& Bush, 2007).

If nurses are unable to determine when weight gain, blood pressure readings, and lightheadedness are related to a HF exacerbation, they cannot properly instruct patients about when to call their physicians. In addition, this lack of knowledge about HF self-management may result in either unnecessary emergency room visits or avoidable hospital stays.

During group discussion of the article and answer key, the participating Care Managers did identify some gaps in their knowledge of HF disease management. Members of the group also expressed the perception that they had acquired new knowledge about HF that was 
applicable to their nursing practice. The Care Managers also expressed the need to develop standardized HF patient education materials to use during home visits. 


\section{Implications for Advanced Practice}

Outcomes of this $\mathrm{HF}$ education program will be disseminated in multiple ways. The analysis of the pre and post-test survey scores will be shared with the HBPC Care Managers during a regularly scheduled staff meeting within the next few months. A PowerPoint presentation summarizing the $\mathrm{HF}$ education program will be made available to the PVAMC Nurse Practice Council for future presentation, pending the chairperson's approval. This researcher will also consider submitting a summary and discussion of this HF education program to an appropriate nursing journal. At the organizational level, advanced practice nurses (APN) must advocate for policies that align resources with desired outcomes. Examples include scheduling continuing education programs to enhance nursing competencies, developing protocols that standardize patient teaching for high risk populations, and using health care technologies, such as telemonitoring of HF patients.

Advanced practice nurses must be life-long learners and engage in continuing education programs like the HF program. They must incorporate this new knowledge into performance improvement projects to promote the application of research-to-practice. The HF education program has stimulated quality improvement initiatives in the HBPC department, for instance, the Care Managers are developing a patient self-management HF zone tool for use in home care. The tool will provide daily reminders for HF symptom monitoring and direct patients when to call a health care professional or to seek emergency services. Implementation of this HF zone tool is intended to improve nurse-to-patient communication during education about self-management principles, with the goals of reducing inappropriate use of emergency services 
and improving patient outcomes. The Care Managers also expressed interest in standardizing HF patient education by developing their own evidenced-based HF handbook, using the Cleveland HF Handbook as an exemplar.

The Affordable Care Act has increased access to health care for many disadvantaged individuals at high risk for HF. With this legislation, more health promotion and disease prevention initiatives are being funded to reduce health care costs. Health promotion and disease prevention are cornerstone concepts in public health nursing and APNs are leading interdisciplinary teams in efforts to decrease tobacco use, improve access to healthy foods, and promote regular physical activity; thereby proving their value in sustaining the health of their communities (Heidenreich, et al., 2011). 


\section{References}

About the cms innovation center. (2012). Retrieved from Centers for Medicare and Medicaid Services: http://innovation.cms.gov/About/index.html

Acute Care Hospital Inpatient Prospective Payment System. (2013, April). Retrieved from Department of Health and Human Services Centers for Medicare and Medicaid: http://www.cms.gov/Outreach-and-Education/Medicare-Learning-NetworkMLN/MLNProducts/downloads/AcutePaymtSysfctsht.pdf

Albert, N. M., Collier, S., Sumodi, V., Wilkinson, S., Hammel, J., Vopat, L., . . Bittel, B. (2002). Nurses' knowledge of heart failure education principles. Heart \& Lung, 2. 102-112.

American Heart Association. (2014, April 14). Retrieved from Get with the guidelines heart failure overview: http://www.heart.org/HEARTORG/HealthcareProfessional/GetWithTheGuidelinesHFStr oke/GetWithTheGuidelinesHeartFailureHomePage/Get-With-The-Guidelines-HeartFailure-Overview_UCM_307806_Article.jsp

American Nurses Association Evidence based nursing position statement. (2005). Retrieved from American Nurses Association :

http://www.nursingsociety.org/aboutus/PositionPapers/Pages/EBN_positionpaoper.asp 
Association, T. C. (1994). Nomenclature and Criteria for Diagnosis of Diseases of the Heart and Great Vessels $\left(9^{\text {th }}\right)$ ed. Boston: Little, Brown\& Co.

DeBakey, M. E., \& Gotto Jr., A. M. (2012). The Living Heart In the 21st Century. Amherst: Prometheus Books.

Fowler, S. (2012). Improving community health nurses' knowledge of heart failure education principles. Home Healthcare Nurse, 30, 91-99.

Get with the guidelines heart failure patient education prior to hospital discharge. (2011, June). Retrieved from American Heart Association: http://www.heart.org/idc/groups/heartpublic/@wcm/@private/@hcm/@gwtg/documents/downloadable/ucm_428949.pdf

Go AS, Mozaffarian D, Roger VL, Benjamin EJ, Berry JD, Borden WB, Bravata DM, Dai S, Ford ES, Fox CS, Franco S, Fullerton HJ, Gillespie C, Hailpern SM, Heit JA, Howard VJ, Huffman MD, Kissela BM, Kittner SJ, Lackland DT, Lichtman JH, Lisabeth LD, Magid D, Marcus GM, Marelli A, Matchar DB, McGuire D, Mohler E, Moy CS, Mussolino ME, Nichol G, Paynter NP, Schreiner PJ, Sorlie PD, Stein J, Turan TN, Virani SS, Wong ND, Woo D, Turner MB; on behalf of the American Heart Association Statistics Committee and Stroke Statistics Subcommittee. Heart disease and stroke statistics-2013 update: a report from the American Heart Association. Circulation.2013: published online before print December 12, 2012, 10.1161/CIR.0b013e31828124ad.

Grady, K., Dracup, K., \& Kennedy, G. (2000). Team management of patients with heart failure: A statement for healthcare professionals from the cardiovascular nursing council of the American Heart Assosiation. Circulation, 102, 2443-2456. 
Heidenreich, P. A., Albert, N. M., Allen, L. A., Bluemke, D. A., Butler, J., Fonarow, G. C., . . . Khavjou, O. (2013). Forcasting the impact of heart failure in the United States. Circulation Journal of the American Heart Association, 2013; 600-00.

Heidenreich, P. A., Trogdon, J. G., Khavjou, O. A., Butler, J., Dracup, K., Ezekowitz, M. D., . . . Johnston, C. (2011). Forecasting the future of cardiovascular disease in the United States. Circulation, 123, 933-944.

Knowles, M. S. (1980). The modern practice of adult education. Chicago: Follett.

Moser, D. K., \& Mann, D. L. (2002). Improving outcomes in heart failure. Circulation Journal of the American Heart Association, 105, 2810-2812.

Paul, S. (2008). Hospital discharge education for patients with heart failure. Critical Care Nurse, 28, 66-82.

Riegel B, Moser DK, Anker SD, Appel U, Dunbar SB, Grady KL, Gurvitz MZ, Havranek EP, Lee CS, Lindenfeld J, Peterson PN, Pressler SJ, Schocken DD, Whellan DJ; on behalf of the American Heart Association Council on Cardiovascular Nursing, Council on Clinical Cardiology, Council on Nutrition, Physical Activity, and Metabolism, and Interdisciplinary Council on Quality of Care and Outcomes Research. State of the science: promoting self-care in persons with heart failure: a scientific statement from the American Heart Association. Circulation. 2009;120:1141-1163.

Schocken, D. D., Benjamin, E. J., Fonarow, G. C., Krumholz, H. M., Levy, D., Mensah, G. A., . . . Hong, Y. (2008). Prevention of heart failure. Circulation Journal of the American Heart Association, 117, 2544-2565. 
TF: Target heart failure. (2011, June). Retrieved from American Heart Association: http://www.heart.org/idc/groups/heartpublic/@wcm/@private/@hcm/@gwtg/documents/downloadable/ucm_428949.pdf

Tomaselli, G. F., Harty, M.-B., Horton, K., \& Schoeberl, M. (2011). The American Heart Association and the million hearts initiative. Circulation Journal of the American Heart Association, 124, 1-5.

W.K. Kellogg. (2004, January). Logic model development guide. Retrieved from W.K. Kellogg Foundation: www.wkkf.org

Willette, E. W., Surrells, D., Davis, L., \& Bush, C. T. (2007). Nurses' knowledge of heart failure self-management. Progress in Cardiovascular Nursing, 22 (4), 190-195. 


\section{Informational Letter}

\section{Appendix A}

\section{Dear Colleague,}

You are being asked to voluntarily participate in a Heart Failure (HF) education program scheduled between January 2014 and March 2014 during regular work hours at the Home Based Primary Care (HBPC) office in Providence. This program is being conducted as part of my Masters project and has been approved by our supervisor, Thomas Mock, Departmental Chief.

The purpose of this HF program is to review and potentially improve Care Manager's current knowledge of HF treatment guidelines. During the first meeting, the program contents and goals will be described. You will be asked to complete the Nurses Knowledge of Heart Failure Education Principles questionnaire, consisting of twenty true or false questions to obtain a baseline score. The score will be anonymous and results will not be reflected in your educational record. To maintain your anonymity, you will develop a unique identifier consisting of three elements, the initial of your father's first name, the initial of your mother's first name, and the number of your older siblings. This identifier will be recorded on the top right corner of the pre-test and post-test to allow the scores to be recorded and compared to evaluate the program's outcomes.

Next, you will be asked to complete the Health. Edu Cardiovascular Topics: Congestive Heart Failure on-line module and post-test located in the Talent Management System (TMS) requiring approximately 1.5 hours to complete. Additionally, you will be given the Heart Failure Handbook from the Louis Stokes Cleveland VAMC for review. 
During the final staff meeting, you will be asked once again to complete the Nurses Knowledge of Heart Failure Education Principles questionnaire anonymously as part of the post program evaluation.

There are no identified risks associated with your participation and you may benefit from completing the questionnaires and online module and by reviewing the handbook to increase your knowledge of HF symptom management and the most current HF treatment guidelines. Your participation would be greatly valued and appreciated. If you have any questions, please contact me at (401) 273-7100 ext. 6707.

Thank you for your consideration,

Suzanne Richmond BSN, RN-BC

Student, Master of Public Health Nursing, Rhode Island College 


\section{Appendix B}

Dear Care Manager:

I would like to assess your educational needs related to instructing patients in heart failure self-management skills. Please complete the following true or false survey questions to assist in the evaluation of your current heart failure knowledge, and to identify areas that could be improved.

Instructions: Please circle either true (yes) or false (no) at the end of each question. Please answer each question. If you do not know the correct answer please make your best guess. Do not place your name on this survey. To maintain your anonymity you will develop a unique identifier consisting of three elements, the initial of your father's first name, the initial of your mother's first name, and the number of your older siblings. Please record this identifier on the top right corner of the pre-test and post-test to allow the scores to be recorded and compared for analysis and to evaluate the program outcomes.

\section{Nurse information:}

Type of employment previous to Home Based Primary Care (please circle and choose only one):

Hospital Emergency department Home care Cardiac unit/ICU Other

Highest educational level (please circle only one):

Diploma nurse Associate's Degree Bachelor's Degree Master's Degree

Total years of case management/care management experience (please include all nursing career experience and circle the answer that most closely applies):

Less than 1 year $\quad 1-3$ yrs. $\quad 4-6$ yrs. Greater than 6 years

Using the scale below, please rate your level of confidence regarding your current knowledge of heart failure principles (please circle only one response):

Very confident Somewhat confident Neutral Not very confident Not at all confident 


\section{Appendix C}

\section{Nurses Knowledge of Heart Failure Principles Survey}

1. Patients with HF should drink plenty of fluids each day.

(True or False)

2. As long as no salt is added to foods, there are no dietary restrictions for patients with HF.

(True or False)

3. Coughing and nausea/poor appetite are common symptoms of advanced HF. (True or False)

4. Patients with HF should decrease activity and most forms of active exercise should be avoided.

(True or False)

5. If the patient gains more than 3 pounds in 48 hours without other HF symptoms, they should not be concerned.

(True or False)

6. Swelling of the abdomen may indicate retention of excess fluid due to worsening HF.

(True or False)

7. If patients take their medications as directed and follow the suggested lifestyle modifications, their HF condition will not return.

(True or False)

8. When patients have aches and pains, aspirin and non-steroidal anti-inflammatory drugs (NSAIDS such as ibuprofen) should be recommended.

(True or False)

9. It is okay to use potassium-based salt substitutes (e.g., "no-salt" or "salt sense") to season foods.

(True or False)

10. If patients feel thirsty, it is okay to remove fluid limits and allow them to drink. (True or False)

11. If a patient adds extra pillows at night to relieve shortness of breath, this does not mean that the HF condition has worsened.

(True or False)

12. If a patient wakes up at night with difficulty breathing, and the breathing difficulty is relieved by getting out of bed and moving around, this does not mean that the HF condition has worsened.

(True or False) 
13. Lean deli meats are an acceptable food choice as part of the patient's diet. (True or False)

14. Once the patient's HF symptoms are gone, there is no need for obtaining daily weights.

(True or False)

15. When assessing weight results, today's weight should be compared with the patient's weight from yesterday, not the patient's ideal or "dry" weight. The following five statements reflect signs or symptoms that patients may have. Mark "yes" (T) or "no" (F) to signify that a patient should notify their HF-physician of these signs or symptoms.

16. BP recording of $80 / 50$ without any HF symptoms. (True/Yes or False/No)

17. Weight gain of 3 pounds in 5 days without symptoms. (True/Yes or False/No)

18. Dizziness or lightheadedness when arising that disappears within 10 to 15 minutes. (True/Yes or False/No)

19. New-onset or worsening fatigue.

20. New-onset or worsening of leg weakness or decreased ability to exercise.

(True/Yes or False/No)

Questionnaire created by Nancy Albert, PhD, CCNS, CCRN, NE-BC, FAHA, FCCM. 


\section{Appendix D}

\section{Texas Tech University Health Sciences Center Cardiovascular Topics: Heart Failure Module Post-test}

After completing the Texas University heart failure on-line module, please complete the questions by choosing one of the multiple choice answers provided.

1) Congestive heart failure (CHF) is a clinical syndrome that results from the heart's inability to

Maintain a constant, stable rhythm

Move blood into the periphery to provide oxygenation to tissue and vital organs

Recover from extreme exertion

Process hormones properly

2) Among the following, which element is NOT a risk factor for CHF?

Smoking

Diabetes

Fish consumption

Excessive alcohol intake

3) A 56 year-old male presents with symptoms of CHF. An echocardiogram reveals decreased function of his heart's left ventricle (LV), and an ejection fraction below 40 percent. What diagnosis best fits this set of symptoms?

Diastolic dysfunction

Systolic dysfunction

Cardiomyopathy

Tachyarrhythmia

4) __ is a common cause of systolic dysfunction.

Valvular heart disease

Degraded connective tissue

Renal insufficiency

Pulmonary embolism

5) A distinguishing pathophysiological characteristic of diastolic dysfunction is

Decreased LV function

Dyslipidemia

Normal LV function

Advanced age 
6) A patient who is symptomatic even while at rest would fit the category of the New York Heart Association Classification system for CHF.

Class I

Class II

Class III

Class IV

7) If CHF is suspected, the healthcare provider should ask about when taking a patient's history.

Peripheral vascular disease

Recent flu diagnosis

Measles

Broken bones

8) According to current evidence-based research, a single, definitive diagnostic test for $\mathrm{CHF}$ is ?

Nonexistent. There is no single diagnostic test for CHF.

A hemoglobin A1C lab test

A chest X-ray

An echocardiogram

9) Which beta-blocker is proven to reduce mortality among patients with diminished LV function?

Lisinopril

Carvedilol

Atenolol

Verapamil

10) When Class I CHF symptoms include reduced LV function, the patient should avoid most calcium channel blockers.

True

False 


\section{Appendix $E$ \\ CONSENT DOCUMENT \\ Rhode Island College}

Nursing Care Manager's Knowledge about Heart Failure Before and After the Implementation of a Heart Failure Education Program

You are being asked to participate in a quality improvement project designed to enhance the Care Manager's knowledge of the most current guidelines for the treatment of heart failure (HF) and symptom management. You were selected as a possible participant because you are a Care Manager in the Home Based Primary Care program at the Providence Veterans Administration Medical Center. Please read this form and ask any questions that you may have before deciding whether to participate in the project.

Suzanne Richmond BSN, RN, a graduate student at Rhode Island College, is conducting this project.

\section{Background Information}

The purpose of this HF education program is to review and potentially improve Care Manager's current knowledge of HF treatment guidelines.

\section{Procedures}

If you choose to be a participant in this project, you will be asked to attend two meetings that will take place during normal work hours. You will be asked to complete pre and post-test questionnaires, an online HF educational module and post-test and review a handbook about HF.

During the first meeting, approximately one hour in duration, the program contents and goals will be described. You will be asked to complete the Nurses Knowledge of Heart Failure Education Principles questionnaire, consisting of twenty, true or false questions to obtain a baseline score. The score will be anonymous and results will not be reflected in your educational record. To maintain your anonymity, you will develop a unique identifier consisting of three elements, the initial of your father's first name, the initial of your mother's first name, and the number of your older siblings. This identifier will be recorded on the top right corner of 
the pre-test and post-test to allow the scores to be recorded and compared to evaluate the program's outcomes.

Next, you will be asked to complete the Health. Edu Cardiovascular Topics: Congestive Heart Failure on-line module and post-test located in the Talent Management System (TMS) requiring approximately 1.5 hours to complete. Additionally, you will be given the Heart Failure Handbook from the Louis Stokes Cleveland VAMC to review.

During the final staff meeting, approximately one hour in duration, we will discuss these educational components and you will then be asked to once again complete the Nurses Knowledge of Heart Failure Education Principles questionnaire anonymously as part of the post program evaluation.

\section{Risks of Being in the Study}

There are no identified risks associated with your participation.

\section{Benefits to You}

There are no direct benefits to you for participating in the project. You may benefit from completing the questionnaires, online module and handbook by increasing your knowledge of HF symptom management and the most current HF treatment guidelines.

\section{Voluntary Participation}

Your participation is completely voluntary. It is not required by the Providence Veterans Administration Medical Center. You can choose not to participate in this project and it will have no effect on your employment. You may also choose not to sign this consent or participate in the pre and post surveys or on-line module and still attend the HF education program meetings. Also, you can change your mind about participating at any time with no negative consequences.

\section{Confidentiality}

The records of this project will be kept private. In any sort of report that might be published, the project leader will not include any information that will make it possible to identify you. Project records will be kept in a secured file, and access will be limited to the project leader. If there are problems with the project, the project leader's records may be 
viewed by the Rhode Island College review board responsible for protecting human participants and other government agencies that protect human participants in research. All data will be kept for a minimum of three years, after which it will be destroyed.

\section{Contacts and Questions}

The nurse conducting this project is Suzanne Richmond BSN, RN. You may ask any questions you may have now. If you have any questions later, you may contact Suzanne at (401) 273-7100 ext.6707. If you think you were treated unfairly or would like to talk to someone other than the project leader about your rights or safety as a research participant, please contact Dr. Christine Marco, Chair of the Rhode Island College Institutional Review Board at IRB@ric.edu, or by phone at 401-456-8598, or by writing to Dr. Christine Marco, Chair IRB; c/o Department of Psychology, Horace Mann Hall 311; Rhode Island College; 600 Mount Pleasant Avenue; Providence, RI 02908.

You will be given a copy of this form for your records. Please print and sign this consent form and bring it with you to the first HF education meeting. There will be additional copies of this consent if a participant's decides to participate or forgets their signed consent.

\section{Statement of Consent}

I have read and understand the information above and I agree to participate in the project “Care Manager's Knowledge about Heart Failure Before and After the Implementation of a Heart Failure Educational Program."

I understand that my participation is voluntary and can be withdrawn at any time with no negative consequences. I have received answers to the questions I asked, or I will contact the project leader with future questions that arise. I am at least 18 years of age.

Print Name of Participant:

Signature of Participant:

Date:

Name of Project Leader Obtaining Consent:

Suzanne Richmond BSN RN, Rhode Island College Graduate Student 